\title{
Effect of spermine on liver and spleen antioxidant status in weaned rats
}

\author{
G. Liu' ${ }^{1,3}$, W. Cao', G. Jia ${ }^{1}$, H. Zhao', X. Chen ${ }^{1}$, J. Wang ${ }^{2}$ and C. Wu ${ }^{1}$ \\ ${ }^{1}$ Institute of Animal Nutrition, Sichuan Agricultural University and Key Laboratory for Animal Disease-Resistance Nutrition \\ of China Ministry of Education, Chengdu 611130, Sichuan, China \\ ${ }^{2}$ Maize Research Institute, Sichuan Agricultural University, Chengdu 611130, Sichuan, China
}

KEY WORDS: spermine, antioxidant status, liver, spleen, weaned rats

Received: $\quad 29$ July 2015

Revised: $\quad 18$ July 2016

Accepted: 25 November 2016
${ }^{3}$ Corresponding author:

e-mail: liugm@sicau.edu.cn

\begin{abstract}
Whereas strong antioxidant properties of spermine have been reported mostly in in vitro studies, there is lack of the in vivo studies on spermine influence conducted on mammals. The main objective of this study was to investigate the effects of different doses of spermine and the period of its supplementation on the liver and spleen antioxidant capacity in weaned rats. Male Sprague-Dawley rats at the age of 19 days received intragastrically spermine at the dose of 0.2 or $0.4 \mu \mathrm{mol} \cdot \mathrm{g}^{-1}$ body weight for 3 or 7 days, respectively. Control rats received saline in analogical way. It was found that liver anti-superoxide anion (ASA) capacity, catalase (CAT) activity, glutathione (GSH) content and total antioxidant capacity (T-AOC) were increased in group supplemented with higher dose of spermine after 3 days, and anti-hydroxy radical (AHR) capacity was increased when treatment lasted for 7 days. In the spleen the higher spermine dose supplementation increased ASA capacity and total superoxide dismutase (T-SOD) activity (after 3 and 7 days), AHR capacity (after 7 days) and T-AOC (after 3 days) in comparison to the corresponding control groups $(P<0.05)$. Only in the spleen the lower spermine dose reduced lipid peroxidation level and increased CAT activity and GSH content regardless treatment duration $(P<0.05)$. The obtained results suggest that spermine supplementation can improve the antioxidant properties of the liver and spleen of weaned rats in a dose-, time- and tissue-dependent manner.
\end{abstract}

\section{Introduction}

While weaning is frequently adopted in animal agriculture to improve economic profit all over the world, the practice presents several problems at the same time. Numerous biological stress responses are evoked by maternal and littermate separations, abrupt changes in society, and environmental changes associated with weaning (Moeser et al., 2007). Weaning stress can contribute to intestinal and immune system dysfunctions by impairing mucosal barrier functions, increasing metabolic disorders and increasing the frequency of diarrhoea incidence (Zhu et al., 2012; Campbell et al., 2013). Previous study showed that weaning can lead to enhanced oxidative stress, which can cause organand pathway-specific toxicity associated with such processes as altered membrane permeability and enhanced apoptosis; oxidative stress also decreases antioxidant defense capacity of the whole organism (Zhu et al., 2012). It was observed that addition of certain bioactive substances (e.g., glutamine and 
herbal additives) into animal feed is an effective approach to reduce oxidative stress induced by weaning.

It is well-known that spermine can be found in the cells of all living organisms as polymeric aliphatic cation of low-molecular weight. It is a necessary regulatory amine for synthesizing proteins and nucleic acids in the animal body; it is also an essential natural intracellular molecule for cell growth and proliferation. Furthermore, spermine contributes to accelerating immune response, preventing oxygen toxicity, mitigating intestinal dysfunction, interacting with numerous intracellular messengers, controlling cell membrane transport and calcium-related signal transduction (Pegg, 2014). Supplementation with appropriate doses of spermine can counteract metabolic consequences and mitigate oxidative injury in weaned rats (Liu et al., 2014), as well as play an important role in promoting gut maturation. Spermine-induced effects in guts can be associated with morphological and physiological alterations, such as weight and length enhancement, villus increase, crypt depth decrease, enzymes activities enhancement/decrease and macromolecular metabolism improvement (Cao et al., 2015; Liu et al., 2015; Fang et al., 2016). Moreover, spermine was reported to be a free radical scavenger, so it can protect mammalian cells from reactive oxygen species (ROS) in vitro (Ha et al., 1998) and improve the antioxidant capacity of the suckling animals serum or duodenum (Cao et al., 2015; Fang et al., 2016). However, there is no information about the relationship between spermine and the antioxidant capacity of weaned animal liver and spleen in vivo.

The liver is the primary detoxifying organ of the body, so it possesses a high metabolic rate connected with high free radical generation, which makes liver particularly vulnerable to the oxidative stress damage. Therefore, maintaining the antioxidant defence system of the liver is very important for preserving good health status. The spleen, on the other hand, is the largest secondary immune organ in the body and is mainly in charge of forming antibodies, differentiating B cells, participating in immune responses, filtering aging erythrocytes, storing blood and initiating immune reactions to blood-borne antigens. In general, animal disease resistance is related to the immune responses of immune organs. Thus, the normal structure and functioning of immune organs are related to animal immunity. Oxidative injury caused by oxidative stress often leads to alteration in the structure and functioning of numerous organs. Hence, maintaining the normal antioxidant status of the spleen and liver is important. As such, further investigation of the effects of different doses of spermine on the antioxidant properties of the liver and spleen is necessary.

This study is a part of a larger study focused on the metabolomic effects of spermine against weaning stress (Liu et al., 2014). The objective of this study was to investigate the effects of different doses of spermine and treatment period on the antioxidant status of the liver and spleen in weaned rats. The obtained results can provide a theoretical basis for spermine development as a weaning stress-resistant component in animal feeds.

\section{Material and methods}

\section{Animal experiment and sample collection}

The protocol of this study was approved by the Care and Use of Laboratory Animals of Sichuan Agricultural University (China), and was conducted in accordance with the Guide for the Care and Use of Laboratory Animals of the National Research Council. All rats were placed in individual metabolic cages and acclimatized to experimental conditions 1 day before the start of the experiment. In total 36 weaned male Sprague-Dawley (SD) rats (Dossy Experimental Animals Co., Ltd., Chengdu, China) aging 19 days and weighing 38-45 g were randomly assigned to 6 experimental groups (i.e. C-3, C-7, S0.2-3, S0.2-7, S0.4-3, S0.4-7), 6 animals in each. Two levels of spermine $(0.2$ and $0.4 \mu \mathrm{mol} \cdot \mathrm{g}^{-1}$ body weight; Sigma Chemical Co., St. Louis, MO, USA) or physiological saline (in control groups) were intragastrically administered using sterile gavage-probe once a day for 3 or 7 days. Rats had ad libitum access to feed and water. Throughout the experiment, the temperature ranged from $22{ }^{\circ} \mathrm{C}$ to $25{ }^{\circ} \mathrm{C}$, humidity - from $50 \%$ to $70 \%$, and 12:12 light:dark cycle was maintained. Weaned SD rats were anesthetized with ether $48 \mathrm{~h}$ after the last spermine application. Liver and spleen samples were quickly removed, frozen in liquid nitrogen, and stored at $-80^{\circ} \mathrm{C}$ until further analyses. The spermine doses and duration of spermine administration in this trial were determined on the basis of previous studies (Deloyer et al., 2005; Liu et al., 2014).

\section{Tissue samples preparation}

Tissue sample preparation was performed according to Zhang et al. (2008). Livers and spleens were rapidly thawed, and ice-cold normal saline was mixed with the samples at a ratio of 9:1 (v/v). The mixture was kept at $4{ }^{\circ} \mathrm{C}$ and then centrifuged at $4000 \mathrm{~g}$ for $15 \mathrm{~min}$ at $4{ }^{\circ} \mathrm{C}$ to collect supernatant. 


\section{Detection of lipid peroxidation}

Malondialdehyde (MDA) content was detected as described by Livingstone et al. (1990) and was measured by using thiobarbituric acid reaction diagnostic kit according to manufacturer instruction (A003-1, Nanjing Jiancheng Biological Engineering Institute, Nanjing, China). The reaction is based on thiobarbituric acid reaction with MDA resulting in a red product featuring absorbance at $532 \mathrm{~nm}$. MDA results are expressed as $\mathrm{nmol} \cdot \mathrm{mg}^{-1}$ protein, and the protein concentration of tissue samples was analysed according to Bradford (1976).

\section{Detection of $\mathrm{O}_{2}^{-}$and $\mathrm{OH}^{-}$-scavenging abilities}

Methods to determine anti-superoxide anion (ASA) capacity $\left(\mathrm{O}_{2}^{-}\right.$-scavenging ability) and antihydroxyl radical (AHR) capacity $\left(\mathrm{OH}^{-}\right.$-scavenging ability) followed the protocol of Jiang et al. (2009). ASA capacity was determined using the Superoxide Anion Free Radical Detection Kit (A052, Nanjing Jiancheng Biological Engineering Institute, Nanjing, China). $\mathrm{O}_{2}^{-}$was generated by the reaction of xanthine and xanthine oxidase. After addition of the electron acceptor, a colouration was developed using the Griess reagent. The colouration degree is directly proportional to the amount of superoxide anion in the sample. Tissue ASA ability is expressed as $\mathrm{U} \cdot \mathrm{g}^{-1}$ protein; here, one unit is the quantity of superoxide anion free radicals scavenged within $40 \mathrm{~min}$ per $g$ of tissue protein, which is equal to each $g$ of vitamin C-scavenging under the same condition. AHR capacity was determined using the Hydroxyl Free Radical Detection Kit (A018, Nanjing Jiancheng Biological Engineering Institute, Nanjing, China). $\mathrm{OH}^{-}$ was generated on the basis of the Fenton reaction $\left(\mathrm{Fe}^{2+}+\mathrm{H}_{2} \mathrm{O}_{2} \rightarrow \mathrm{Fe}^{3+}+\mathrm{OH}^{-}+\mathrm{OH}\right)$. After addition of the electron acceptor, a colouration reaction was developed using the Griess reagent. The colouration degree is directly proportional to the quantity of hydroxyl radicals in the reaction. Tissue AHR capacity is expressed in $\mathrm{U} \cdot \mathrm{mg}^{-1}$ protein; here, one unit is defined as the amount that decreases $1 \mathrm{mmol} \cdot 1^{-1} \mathrm{H}_{2} \mathrm{O}_{2}$ within $1 \mathrm{~min}$ per $\mathrm{mg}$ of tissue protein.

\section{Antioxidant enzymes activity assay}

Total superoxide dismutase (T-SOD) activity was determined according to the instruction of T-SOD test kit (A001-1, Nanjing Jiancheng Biological Engineering Institute, Nanjing, China). Tissue T-SOD activity is expressed as $\mathrm{U} \cdot \mathrm{mg}^{-1}$ protein; here, one unit means
$50 \%$ inhibition of nitric ion production by SOD. Catalase (CAT) activity was assayed in accordance to the method described by Aebi (1984) and operating process followed the instruction of CAT measurement kit (A007-1, Nanjing Jiancheng Biological Engineering Institute, Nanjing, China). CAT activity is expressed in $\mathrm{U} \cdot \mathrm{mg}^{-1}$ protein. Here, one unit is defined as the quantity that decreased $1 \mathrm{mmol} \cdot 1^{-1} \mathrm{H}_{2} \mathrm{O}_{2}$ within $1 \mathrm{~s}$ per $\mathrm{mg}$ of tissue protein.

\section{GSH content analysis}

Glutathione (GSH) content in tissues homogenates was measured in terms of formation of 5-thio-2-nitrobenzoate detected spectrophotometrically at $412 \mathrm{~nm}$ (Vardi et al., 2008) according to the instruction of GSH assay kit (A006-1, Nanjing Jiancheng Biological Engineering Institute, Nanjing, China). GSH content in the extract was expressed in $\mathrm{mg} \cdot \mathrm{g}^{-1}$ protein using commercial GSH as a standard.

\section{Total antioxidant capacity measurement}

Total antioxidant capacity (T-AOC) activity was estimated by using T-AOC detection kit according to manufacturer instruction (A015, Nanjing Jiancheng Biological Engineering Institute, Nanjing, China) and assay method according to the colorimetric technique as described by Benzie and Strain (1996). All endogenous antioxidants of the body were able to reduce $\mathrm{Fe}^{3+}$ to $\mathrm{Fe}^{2+}$, and the latter can develop coloured and stable chelates when combined with phenanthroline. T-AOC is represented as $\mathrm{U} \cdot \mathrm{mg}^{-1}$ protein; here, one unit of T-AOC is defined as the absorbance value that increases by 0.01 within $1 \mathrm{~min}$ per $\mathrm{mg}$ of tissue protein.

\section{Statistical analysis}

All experimental data were subjected to twoway analysis of variance (ANOVA) using the general linear model procedure of SPSS 17.0 software (SPSS Inc., Chicago, IL, USA) with previous checking of ANOVA assumptions about normality and homogeneity of variances using Shapiro-Wilk's W-test and Levene's test, respectively. The main effects of the obtained model included: spermine level $(0,0.2$, $0.4 \mu \mathrm{mol} \cdot \mathrm{g}^{-1}$ body weight) and treatment duration (3 or 7 days). Statistical differences between examined groups were deter-mined using the Duncan's multiple range. The differences were considered statistically significant at $P<0.05$. All results are presented as mean value \pm standard error. 


\section{Results}

\section{Lipid peroxidation and antioxidant parameters in liver (Table 1)}

In liver, the lipid peroxidation was not influenced by spermine addition regardless dose and period of supplementation.

The 7-day supplementation with higher dose of spermine increased anti-superoxide anion (ASA) capacity (C-7 vs S0.4-7); however the 3-day supplementation with the same spermine dose increased anti-hydroxy radical (AHR) capacity (C-3 vs S0.4-3). The supplementation extension of lower dose of spermine caused higher AHR capacity (S0.2-3 vs S0.2-7); however the obtained value did not differ from values observed for C-7 and S0.4-7 groups. Moreover, there was observed a difference between $\mathrm{C} 3$ and $\mathrm{C}-7$ group.

There was observed no influence of spermine on total superoxide dismutase (T-SOD) activity in liver. The liver catalase (CAT) activity was higher in group which received higher dose of spermine for 3 days in comparison to control group (C-3 vs S0.4-3). The extension of supplementation duration for lower spermine dose increased CAT activity to value which did not differ from values observed for S0.4-7 and S0.4-3 groups but also from C-7 group.

The glutathione (GSH) content was higher in S0.4-3 group in comparison to both C-3 and S0.2-3 groups. The supplementation extension of both lower and higher doses of spermine caused higher GSH content; however the obtained value did not differ from C-7 group. Moreover, the GSH content was increased in $\mathrm{C} 7$ in comparison to $\mathrm{C} 3$ group.

The liver total antioxidant capacity (T-AOC) was higher in S0.4-3 group in comparison to both C-3 and S0.2-3 group; however S0.4-3 group did not differ from all groups supplemented for 7 days.

\section{Lipid peroxidation and antioxidant parameters in spleen (Table 2)}

The spleen lipid peroxidation level was reduced by both doses of spermine, regardless of the treatment duration (S0.2-3 and S0.4-3 vs C-3; S0.2-7 and S0.4-7 vs C-7). The higher dose of spermine caused higher decrease of MDA content than the lower one but only after 3 days of supplementation (S0.2-3 vs S0.4-3). The supplementation extension of both doses of spermine caused further MDA content decrease (S0.2-3 vs S0.2-7 and S0.4-3 vs S0.4-7); however there was observed no difference between S02-7 and S0.4-7 groups.

The spleen ASA capacity was higher in groups that received the higher spermine dose in comparison to the corresponding control groups, regardless of supplementation time (C-3 vs S0.4-3 and C-7 vs S0.4-7). AHR capacity was higher only in group S0.4-7 in comparison to C-7 group. The extension of supplementation period of lower spermine dose increased the ASA capacity ( $\mathrm{S} 0.2-3$ vs $\mathrm{S} 0.2-7$ ) to value which did not differ from S0.4-7 and S0.4-3. On the other hand, the extension of supplementation duration of higher spermine dose increased the AHR capacity (S0.4-3 vs S0.4-7).

Table 1. Effects of spermine dose (S) and supplementation time (T) on lipid peroxidation and antioxidant status of liver in weaned rats

\begin{tabular}{|c|c|c|c|c|c|c|c|c|c|c|}
\hline \multirow{2}{*}{ Indices $^{2}$} & \multicolumn{3}{|l|}{ Group ${ }^{1}$} & \multirow[b]{2}{*}{$\overline{\mathrm{C}-7}$} & \multirow[b]{2}{*}{ S0.2-7 } & \multirow[b]{2}{*}{ S0.4-7 } & \multirow{2}{*}{ SEM } & \multicolumn{3}{|c|}{$P$-value } \\
\hline & $\mathrm{C}-3$ & S0.2-3 & S0.4-3 & & & & & $S$ & $T$ & $S \times T$ \\
\hline $\begin{array}{l}\text { MDA content, } \\
\mathrm{nmol} \cdot \mathrm{mg}^{-1} \text { protein }\end{array}$ & 1.02 & 0.77 & 0.79 & 0.66 & 0.82 & 0.75 & 0.03 & 0.604 & 0.054 & 0.017 \\
\hline $\begin{array}{l}\text { ASA capacity, } \\
\mathrm{U} \cdot \mathrm{g}^{-1} \text { protein }\end{array}$ & $132.34^{\mathrm{ab}}$ & $132.39 \mathrm{ab}$ & $143.25^{b}$ & $119.45^{\mathrm{a}}$ & $134.38^{\mathrm{ab}}$ & $139.74^{b}$ & 2.30 & 0.015 & 0.256 & 0.350 \\
\hline $\begin{array}{l}\text { AHR capacity, } \\
\qquad \mathrm{U} \cdot \mathrm{mg}^{-1} \text { protein }\end{array}$ & $181.82^{\mathrm{a}}$ & $199.17^{\mathrm{ab}}$ & $237.30^{\mathrm{bc}}$ & $223.16^{\text {bc }}$ & $251.39^{c}$ & $255.88^{c}$ & 6.90 & 0.008 & 0.002 & 0.443 \\
\hline $\begin{array}{l}\text { T-SOD activity, } \\
\mathrm{U} \cdot \mathrm{mg}^{-1} \text { protein }\end{array}$ & 38.58 & 38.95 & 43.56 & 36.73 & 40.68 & 40.34 & 0.75 & 0.058 & 0.440 & 0.369 \\
\hline $\begin{array}{l}\text { CAT activity, } \\
\qquad \mathrm{U} \cdot \mathrm{mg}^{-1} \text { protein }\end{array}$ & $89.52^{\mathrm{a}}$ & $96.16^{\mathrm{ab}}$ & $113.70^{\mathrm{bc}}$ & $108.38^{\mathrm{abc}}$ & $116.25^{c}$ & $122.64^{c}$ & 3.26 & 0.023 & 0.007 & 0.661 \\
\hline $\begin{array}{l}\text { GSH content, } \\
\mathrm{mg} \cdot \mathrm{g}^{-1} \text { protein }\end{array}$ & $1.77^{\mathrm{a}}$ & $1.88^{a}$ & $3.08^{b}$ & $3.72^{\mathrm{bc}}$ & $4.03^{c}$ & $4.08^{c}$ & 0.20 & 0.015 & 0.000 & 0.109 \\
\hline $\begin{array}{l}\text { T-AOC, } \\
\mathrm{U} \cdot \mathrm{g}^{-1} \text { protein }\end{array}$ & $0.75^{a}$ & $0.78^{a}$ & $0.93^{b}$ & $0.85^{\mathrm{ab}}$ & $0.88^{\mathrm{ab}}$ & $0.93^{b}$ & 0.02 & 0.014 & 0.051 & 0.449 \\
\hline
\end{tabular}

'groups: C-3 and C-7 - control groups receiving saline for 3 and 7 days, respectively; S0.2-3 and S0.2-7 - groups receiving spermine at a dose of $0.2 \mu \mathrm{mol} \cdot \mathrm{g}^{-1}$ body weight for 3 and 7 days, respectively; S0.4-3 and S0.4-7 - group receiving spermine at a dose of $0.4 \mu \mathrm{mol} \cdot \mathrm{g}^{-1}$ body weight for 3 and 7 days, respectively; ${ }^{2} \mathrm{MDA}$ - malondialdehyde, ASA - anti-superoxide anion, ARH - anti-hydroxy radical, T-SOD - total superoxide dismutase, CAT - catalase, GSH - glutathione, T-AOC - total antioxidant capacity; abc - means with different superscripts within a row are significantly different at $P<0.05$ 
Table 2. Effects of spermine dose (S) and supplementation time (T) on lipid peroxidation and antioxidant status of spleen in weaned rats

\begin{tabular}{|c|c|c|c|c|c|c|c|c|c|c|}
\hline \multirow{2}{*}{ Indices $^{1}$} & \multicolumn{3}{|l|}{ Group $^{2}$} & \multirow[b]{2}{*}{ C-7 } & \multirow[b]{2}{*}{ S0.2-7 } & \multirow[b]{2}{*}{ S0.4-7 } & \multirow{2}{*}{ SEM } & \multicolumn{3}{|c|}{$P$-value } \\
\hline & $\mathrm{C}-3$ & S0.2-3 & S0.4-3 & & & & & $S$ & $\mathrm{~T}$ & $S \times T$ \\
\hline $\begin{array}{l}\text { MDA content, } \mathrm{nmol} \cdot \mathrm{mg}^{-1} \\
\text { protein }\end{array}$ & $1.44^{\mathrm{e}}$ & $0.92^{c}$ & $0.69^{b}$ & $1.05^{\mathrm{d}}$ & $0.51^{a}$ & $0.40^{\mathrm{a}}$ & 0.06 & 0.000 & 0.000 & 0.358 \\
\hline $\begin{array}{l}\text { ASA capacity, } U \cdot g^{-1} \\
\text { protein }\end{array}$ & $36.83^{a}$ & $44.59^{a b}$ & $50.10^{\mathrm{bcd}}$ & $47.10^{\mathrm{abc}}$ & $55.96^{\mathrm{cd}}$ & $60.32^{d}$ & 1.88 & 0.003 & 0.001 & 0.928 \\
\hline $\begin{array}{l}\text { AHR capacity, } \mathrm{U} \cdot \mathrm{mg}^{-1} \\
\quad \text { protein }\end{array}$ & $121.53^{\mathrm{a}}$ & $126.64^{\mathrm{ab}}$ & $130.96^{\mathrm{ab}}$ & $134.97^{\mathrm{ab}}$ & $139.85^{b}$ & $160.84^{c}$ & 2.99 & 0.008 & 0.000 & 0.213 \\
\hline $\begin{array}{l}\mathrm{T} \text {-SOD activity, } \mathrm{U} \cdot \mathrm{mg}^{-1} \\
\text { protein }\end{array}$ & $11.14^{a}$ & $12.91^{\mathrm{ab}}$ & $13.78^{\mathrm{bc}}$ & $12.14^{\mathrm{ab}}$ & $14.05^{\mathrm{bc}}$ & $16.20^{c}$ & 0.41 & 0.001 & 0.027 & 0.627 \\
\hline $\begin{array}{l}\text { CAT activity, } \mathrm{U} \cdot \mathrm{mg}^{-1} \\
\text { protein }\end{array}$ & $16.84^{a}$ & $24.53^{b}$ & $28.25^{\mathrm{bc}}$ & $18.84^{\mathrm{a}}$ & $25.26^{b}$ & $30.41^{c}$ & 1.01 & 0.000 & 0.193 & 0.867 \\
\hline $\begin{array}{l}\mathrm{GSH} \text { content, } \mathrm{mg} \cdot \mathrm{g}^{-1} \\
\text { protein }\end{array}$ & $2.55^{\mathrm{a}}$ & $3.29^{b}$ & $3.46^{\mathrm{b}}$ & $2.60^{\mathrm{a}}$ & $3.40^{b}$ & $3.63^{b}$ & 0.12 & 0.000 & 0.506 & 0.959 \\
\hline $\mathrm{T}$-AOC, $\mathrm{U} \cdot \mathrm{g}^{-1}$ protein & $0.83^{a}$ & $0.98^{\mathrm{ab}}$ & $1.05^{b}$ & $0.97^{\mathrm{ab}}$ & $1.04^{b}$ & $1.11^{\mathrm{b}}$ & 0.02 & 0.005 & 0.039 & 0.629 \\
\hline
\end{tabular}

${ }_{1,2}$ see Table $1 ;$ a-e - means with different superscripts within a row are significantly different at $P<0.05$

T-SOD activity was higher in groups that received the higher spermine dose in comparison to corresponding control groups, regardless of supplementation time (C-3 vs S0.4-3 and C-7 vs S0.4-7). Although, the CAT activity was higher in groups that received both doses of spermine in comparison to the corresponding control groups regardless of supplementation time (C-3 vs S0.2-3 and S0.4-3, C-7 vs S0.2-7 and S0.4-7). Moreover, the CAT activity was increased in group S0.4-7 in comparison to S0.2-7.

GSH content was higher in groups that received both doses of spermine in comparison to the corresponding control groups regardless of supplementation time (C-3 vs S0.2-3 and S0.4-3, C-7 vs S0.2-7 and $\mathrm{S} 0.4-7)$. The spleen T-AOC was increased in S0.4-3 group compared to C-3 group.

\section{Discussion}

Weaned animals usually suffer from weaning stress (Campbell et al., 2013). Weaning stress can damage the health status by disrupting the steadystate status of reactive oxygen species (ROS) and suppressing non-enzymatic substances (e.g., GSH) and antioxidant enzyme activities (e.g., SOD and CAT), thereby affecting many production efficiencies, including feed intake, morbidity, growth performance and mortality (Campbell et al., 2013; Zhu et al., 2013). The supplementation of natural antioxidants, such as vitamin $\mathrm{E}$ and spermine, has been practiced to reduce signs of stress in livestock husbandry. The important role of spermine can be underlined by the fact that it is a natural milk component although its concentration is very low (Romain et al., 1992). The effects of spermine on the body can be treatment dose-depended. It was confirmed that exorbitant dose of spermine have numerous side effects, such as reduced microbe, tumors development, growth decrease and even cell death (Cipolla et al., 2010). On the other hand, spermine at the appropriate dose can exert beneficial effects, including intestinal growth promotion and the antioxidant capacity improvement (Cao et al., 2015).

Effects of spermine supplementation dose on the lipid peroxidation and antioxidant status of the liver and spleen. MDA is the most common breakdown product of lipid peroxidation (Pirinccioglu et al., 2010) and its level can directly reflect the degree of lipid oxidative damage. In the present study, the MDA content in the spleen decreased after spermine administration (regardless dose and supplementation duration), whereas no significant difference was found in the liver, which may be attributed to the tissue specific differences (e.g., different fat content in liver and spleen). The obtained results are the first to show the positive influence of spermine on lipid peroxidation level in the spleen with the use of in vivo model.

Lipid peroxidation damage is mainly induced by superoxide anions and hydroperoxyl radicals (Valko et al., 2007). The superoxide anion, which is regarded as the primary ROS, can further interact with other molecules to generate other ROS types and cause a wide range of oxidative damage to organism within the cell (Valko et al., 2007). In this study, the superoxide anion scavenging ability in the liver and spleen of spermine-treated rats was higher in comparison to control group, however in both tissues only higher dose of sperimine $\left(0.4 \mu \mathrm{mol} \cdot \mathrm{g}^{-1}\right.$ body weight) exerted such effect. Such results are in accordance with the results of Kafy et al. (1986) who observed that spermine scavenges superoxide 
anion free radicals only at the very high dose in in vitro model. However, Das and Misra (2004) did not confirmed these results. The observed differences may be attributed to the different experimental models: in vivo and in vitro with the use of in cell and cell-free models.

The next important radical is hydroxyl radical, which can react rapidly with all types of molecules, such as DNA, proteins and lipids, and exhibits a very short half-life of approximately $10^{-9} \mathrm{~s}$ in vivo. This extremely dangerous free radical may cause lipid peroxidation, nuclear acid fracture and decomposition of protein and polysaccharide. Our study showed that the $\mathrm{OH}^{-}$-scavenging ability in the liver and spleen was significantly increased with spermine supplementation but only when higher dose of spermine was administrated for 3 or 7 days. Such observations are in line with other researches indicating that spermine is mostly a hydroxyl radical scavenger which has the singlet oxygen quenching properties. Sava et al. (2006) proposed mechanism based on a Fenton-like reaction system with spermine dialdehyde as a final product, which was consistent with the results of a previous in vitro study conducted by $\mathrm{Ha}$ et al. (1998). So, these findings indicate that spermine administration can improve the free radical scavenging ability in the tissues.

Free radical scavenging abilities are related to enzymatic and non-enzymatic antioxidant defence systems (Valko et al., 2007). The major enzymatic antioxidants (e.g., T-SOD and CAT) are necessary to prevent the body from biological stress influence. SOD is the first endogenous antioxidant enzyme which responds to oxygen radicals and transform superoxide anions into $\mathrm{H}_{2} \mathrm{O}_{2}$ with lowered toxicity. In the present study it was found that the T-SOD activity in the spleen was significantly enhanced by spermine ingestion higher dose regardless of treatment time. No such effect was observed in liver. The obtained results suggest that spermine supplementation can enhance the SOD activity in weaned rat, but in tissue-dependent manner. CAT, an antioxidant downstream enzyme of SOD, is implicated as an essential defence enzyme against the potential toxicity of hydroxyl radicals. It can detoxify $\mathrm{H}_{2} \mathrm{O}_{2}$ to $\mathrm{H}_{2} \mathrm{O}$ and $\mathrm{O}_{2}$, thus preventing organisms from hydroxyl radicals generation (David et al., 2008). The present experiment showed that spermine administration significantly increased the CAT activity in both examined tissues, however in the spleen the spermine exerted effect at both used doses regardless period of supplementation, and in liver only higher dose supplemented for
3 days exerted such effect. This demonstrated that spermine supplementation can improve the CAT antioxidant property in weaned rats. So, obtained results revealed that spermine supplementation can improve the antioxidant status through enzymatic systems in weaned rats.

In addition, non-enzymatic antioxidant substances, such as GSH, are also important components of organism antioxidant defence system. GSH plays an essential role in damage elimination caused by free radicals and in balance between the intracellular oxidation status and cell integrity maintain (Mallikarjuna et al., 2007). Therefore, GSH is considered as a suitable indicator of cellular antioxidant defence ability. In the current study, spermine supplementation improved the GSH contents in rat liver (only higher spermine dose after the 3 days of supplementation) and spleen (both doses of spermine regardless period of supplementation), which suggested that spermine can enhance the antioxidant defence capacity at least in part because of the increase in GSH content. This finding is in line with our previous study, in which it was showed that spermine can increase the ileum GSH content in suckling rats (Liu et al., 2015). Liver is the main place for GSH generation, and the mechanism of GSH content enhancement caused by spermine supplementation needs further investigation. T-AOC can serve as an important integrative index that reflects the total antioxidant capacity of the organism (Ren et al., 2012). The current study showed that the T-AOC in the liver and spleen were significantly increased after spermine administration but only after 3 days of higher dose supplementation. These data also demonstrated that spermine can improve T-AOC of the selected tissues and protect them from biological stress. Collectively, spermine supplementation can improve the antioxidant status through non-enzymatic antioxidant system in weaned rats.

Dietary supplementation of spermine at a dose of $0.4 \mu \mathrm{mol} \cdot \mathrm{g}^{-1}$ body weight exerted better effect on enhancing the antioxidant status than lower spermine doses $\left(0.2 \mu \mathrm{mol} \cdot \mathrm{g}^{-1}\right.$ body weight $)$ supplementation in weaned rat tissues. In the liver only the supplementation of a higher dose increased AHR capacity, ASA capacity, CAT activity, GSH content and T-AOC. On the other hand, in the spleen even the application of a lower dose exerted positive effect on MDA content, CAT activity and GSH content, whereas only the higher spermine dose influenced ASA and AHR capacity or T-AOC. So, it can be suggested that the antioxidant effect of 
spermine on the spleen is superior to that exerted on the liver. The possible reason is that spleen is the largest secondary immune organ and its responses are associated with the antioxidant status, while liver is the main detoxifying organ and may consume more antioxidant compounds for detoxifying effect, which could cause that the effect of spermine in the liver is not so pronounced.

Effects of extended spermine administration on the antioxidant properties in liver and spleen. The activity of intestinal disaccharide enzyme is altered by spermine ingestion in animals, and spermine treatment generally requires 3 days to observe the effect (Peulen and Dandrifosse, 2000). No research on the effects of the extended spermine administration on the antioxidant defence system of metabolic or immune organ in weaning animals is available. Our study showed that the spleen MDA content was reduced by both doses of spermine regardless of the treatment duration. Also, the supplementation extension for both doses caused further MDA content decrease; however after 7 days of supplementation no difference between doses was observed. These results suggested that prolonging spermine administration can prevent lipid peroxidation in the spleen. Moreover, both the AHR and ASA capacity were significantly increased in the spleen, by the extension of spermine supplementation. These data demonstrated that the extension of spermine supplementation can improve the free radical-scavenging capacity in the spleen and protect this organ from oxidative damage. On the other hand, in the liver the extended spermine supplementation significantly enhance the AHR capacity, CAT activity and GSH content. However such observations were accompanied by increased AHR capacity and GSH content in control group after 7 days of the experiment, which suggests that the observed effect was not connected to the prolonged spermine supplementation but it was only physiological. So, observed differences between spleen and liver suggest that extended spermine supplementation exerts tissue-dependent effect.

\section{Conclusions}

This is the first study to indicate that spermine supplementation can modulate the antioxidant properties of the weaning rat liver and spleen in a dose-, time- and tissue-dependent manner. Nevertheless, the mechanism by which spermine supplementation increases antioxidant status is the most interesting topic for our further examination.

\section{Acknowledgements}

This study was financially supported by the National Natural Science Foundation of China (No. 31301986) and supported by Program for Discipline Construction in Sichuan Agricultural University (to G. Liu). The authors would like to thank the team personnel for their ongoing assistance.

\section{References}

Aebi H., 1984. Catalase in vitro. Methods Enzymol. 105, 121-126, https://doi.org/10.1016/S0076-6879(84)05016-3

Benzie I.F.F., Strain J.J., 1996. The ferric reducing ability of plasma (FRAP) as a measure of "antioxidant power": the FRAP assay. Anal. Biochem. 239, 70-76, https://doi.org/10.1006/ abio.1996.0292

Bradford M.M., 1976. A rapid and sensitive method for the quantitation of microgram quantities of protein utilizing the principle of protein-dye binding. Anal. Biochem. 72, 248-254, https://doi. org/10.1016/0003-2697(76)90527-3

Campbell J.M., Crenshaw J.D., Polo J., 2013. The biological stress of early weaned piglets. J. Anim. Sci. Biotechnol. 4, 19, https://doi. org/10.1186/2049-1891-4-19

Cao W., Liu G., Fang T., Wu X., Jia G., Zhao H., Chen X., Wu C., Wang J., Cai J., 2015. Effects of spermine on the morphology, digestive enzyme activities, and antioxidant status of jejunum in suckling rats. RSC Adv. 5, 76607-76614, https://doi.org/10.1039/ C5RA15793E

Cipolla B.G., Havouis R., Moulinoux J.-P., 2010. Polyamine reduced diet (PRD) nutrition therapy in hormone refractory prostate cancer patients. Biomed. Pharmacother. 64, 363-368, https://doi. org/10.1016/j.biopha.2009.09.022

Das K.C., Misra H.P., 2004. Hydroxyl radical scavenging and singlet oxygen quenching properties of polyamines. Mol. Cell. Biochem. 262, 127-133, https://doi.org/10.1023/B:MCBI.0000038227.91813.79

David M., Munaswamy V., Halappa R., Marigoudar S.R., 2008. Impact of sodium cyanide on catalase activity in the freshwater exotic carp, Cyprinus carpio (Linnaeus). Pestic. Biochem. Phys. 92, 15-18, https://doi.org/10.1016/j.pestbp.2008.03.013

Deloyer P., Peulen O., Dandrifosse G., 2005. Intestinal effects of longlasting spermine ingestion by suckling rats. Exp. Physiol. 90, 901-908, https://doi.org/10.1113/expphysiol.2005.031583

Fang T., Liu G., Cao W., Wu X., Jia G., Zhao H., Chen X., Wu C., Wang J., 2016. Spermine: new insights into the intestinal development and serum antioxidant status of suckling piglets. RSC Adv. 6 , 31323-31335, https://doi.org/10.1039/C6RA05361K

Ha H.C., Sirisoma N.S., Kuppusamy P., Zweier J.L., Woster P.M., Casero R.A. Jr., 1998. The natural polyamine spermine functions directly as a free radical scavenger. Proc. Natl. Acad. Sci. U.S.A. 95, 11140-11145, https://doi.org/10.1073/pnas. 95.19.11140

Jiang J., Zheng T., Zhou X.-Q., Liu Y., Feng L., 2009. Influence of glutamine and vitamin $\mathrm{E}$ on growth and antioxidant capacity of fish enterocytes. Aquacult. Nutr. 15, 409-414, https://doi. org/10.1111/j.1365-2095.2008.00605.x

Kafy A.M.L., Haigh C.G., Lewis D.A., 1986. In vitro interactions between endogenous polyamine and superoxide anion. Agents Actions 18, 555-559, https://doi.org/10.1007/BF01964964

Liu G., Fang T., Yan T., Jia G., Zhao H., Huang Z., Chen X., Wang J., Xue B., 2014. Metabolomic strategy for the detection of metabolic effects of spermine supplementation in weaned rats. J. Agric. Food Chem. 62, 9035-9042, https://doi. org/10.1021/j5500882t 
Liu G., Yan T., Fang T., Jia G., Chen X., Zhao H., Wang J., Wu C., 2015. Nutrimetabolomic analysis provides new insights into spermine-induced ileum-system alterations for suckling rats. RSC Adv. 5, 48769-48778, https://doi.org/10.1039/ C5RA01507C

Livingstone D.R., Martinez P.G., Michel X., Narbonne J.F., O'Hara S., Ribera D., Winston G.W., 1990. Oxyradical production as a pollution-mediated mechanism of toxicity in the common mussel, Mytilus edulis L., and other molluscs. Funct. Ecol. 4, 415-424, https://doi.org/10.2307/2389604

Mallikarjuna K., Nishanth K., Sathyavelu Reddy K., 2007. Hepatic glutathione mediated antioxidant system in ethanol treated rats: decline with age. Pathophysiology 14, 17-21, https://doi. org/10.1016/j.pathophys.2006.09.005

Moeser A.J., Ryan K.A., Nighot P.K., Blikslager A.T., 2007. Gastrointestinal dysfunction induced by early weaning is attenuated by delayed weaning and mast cell blockade in pigs. Am. J. Physiol. Gastrointest. Liver Physiol. 293, G413-G421, https://doi.org/10.1152/ajpgi.00304.2006

Pegg A.E., 2014. The function of spermine. IUBMB Life 66, 8-18, https://doi.org/10.1002/iub.1237

Peulen O., Dandrifosse G., 2000. Cyclosporine A inhibits partially spermine-induced differentiation but not cell loss of suckling rat small intestine. Digest. Dis. Sci. 45, 750-754, https://doi. org/10.1023/A:1005451928488

Pirinccioglu A.G., Gökalp D., Pirinccioglu M., Kizil G., Kizil M., 2010. Malondialdehyde (MDA) and protein carbonyl (PCO) levels as biomarkers of oxidative stress in subjects with familial hypercholesterolemia. Clin. Biochem. 43, 1220-1224, https:// doi.org/10.1016/j.clinbiochem.2010.07.022

Ren W., Yin Y., Liu G., Yu X., Li Y., Yang G., Li T., Wu G., 2012. Effect of dietary arginine supplementation on reproductive performance of mice with porcine circovirus type 2 infection. Amino Acids 42, 2089-2094, https://doi.org/10.1007/s00726011-0942-y
Romain N., Dandrifosse G., Jeusette F., Forget P., 1992. Polyamine concentration in rat milk and food, human milk, and infant formulas. Pediatr. Res. 32, 58-63, https://doi.org/10.1203/00006450 $-199207000-00011$

Sava I.G., Battaglia V., Rossi C.A., Salvi S., Toninello A., 2006. Free radical scavenging action of the natural polyamine spermine in rat liver mitochondria. Free Radic. Biol. Med. 41, 1272-1281, https://doi.org/10.1016/j.freeradbiomed.2006.07.008

Valko M., Leibfritz D., Moncol J., Cronin M.T.D., Mazur M., Telser J., 2007. Free radicals and antioxidants in normal physiological functions and human disease. Int. J. Biochem. Cell Biol. 39, 44-84, https://doi.org/10.1016/j.biocel.2006.07.001

Vardi N., Parlakpinar H., Ozturk F., Ates B., Gul M., Cetin A., Erdogan A., Otlu A., 2008. Potent protective effect of apricot and $\beta$-carotene on methotrexate-induced intestinal oxidative damage in rats. Food Chem. Toxicol. 46, 3015-3022, https:// doi.org/10.1016/j.fct.2008.05.039

Zhang X.D., Zhu Y.F., Cai L.S., Wu T.X., 2008. Effects of fasting on the meat quality and antioxidant defenses of market-size farmed large yellow croaker (Pseudosciaena crocea). Aquaculture 280, 136-139, https://doi.org/10.1016/j.aquaculture.2008.05.010

Zhu L., Cai X., Guo Q., Chen X., Zhu S., Xu J., 2013. Effect of $\mathrm{N}$-acetyl cysteine on enterocyte apoptosis and intracellular signalling pathways' response to oxidative stress in weaned piglets. Br. J. Nutr. 110, 1938-1947, https://doi.org/10.1017/ S0007114513001608

Zhu L.H., Zhao K.L., Chen X.L., Xu J.X., 2012. Impact of weaning and an antioxidant blend on intestinal barrier function and antioxidant status in pigs. J. Anim. Sci. 90, 2581-2589, https://doi.org/10.2527/jas.2011-44 